\title{
IGUALDADES E DESSIMETRIAS: A PARTICIPAÇÃO POLÍTICA EM ONGs HIV/AIDS DO CANADÁ E DO BRASIL
}

\author{
Carlos Roberto de Castro-Silva \\ Universidade Cruzeiro do Sul, São Paulo, Brasil \\ W. E. (Ted) Hewitt \\ University of Western Ontario, Ontario, Canadá \\ Silvana Cavichioli \\ Universidade de Guarulhos, Guarulhos, Brasil
}

\begin{abstract}
RESUMO: As ONGs/AIDS desde o início da epidemia são lugares de acolhimento e de pressão política, propiciam alternativas de convivência social para as pessoas que convivem com o HIV/AIDS. Através da experiência dos participantes de uma ONG brasileira e de outra canadense, este estudo teve o objetivo de discutir a participação política como um processo em constante construção, condicionada por fatores psicossociais, contextualizados histórica e culturalmente. Através da análise de documentos, questionários e entrevistas baseado na Hermenêutica de Profundidade de John Thompson (1995), pudemos perceber que em ambas as ONGs desencadeia-se um processo de politização da AIDS a partir da ajuda ao próximo e das troca de experiências. Todavia na ONG brasileira este processo acontece através de um envolvimento mais intenso com a dinâmica institucional e comunitária, tendo como objetivo a conquista e consolidação de direitos, enquanto que a ONG canadense constitui-se um espaço através do qual cada participante individualmente acessa direitos já consolidados no país.
\end{abstract}

PALAVRAS-CHAVE: Participação política; ONGs/AIDS; fatores psicossociais; direitos humanos; vulnerabilidade social.

\section{SIMILARITIES AND DISSIMILARITIES: POLITICAL PARTICIPATION IN NGOS/AIDS FROM BRAZIL AND CANADA}

ABSTRACT: Since the beginning of the HIV/AIDS epidemic, Non Governmental Organizations (NGOs) have been important places for harboring people that live with HIV/AIDS because they feel welcomed and supported to fight for their rights. By studying the experiences of participants of a Brazilian NGO and a Canadian NGO, this study discussed the political participation as a process which is associated with psychosocial factors, historically and culturally contextualized. We could perceive that, in both NGOs, the politicization process of AIDS started from the perspective of helping other people and sharing experiences related to HIV/AIDS, through the analyze of documents, questionnaires and interviews, based on Hermeneutic of Depth by John Thompson (1995). Yet, in the Brazilian NGO the politicization process occurred through a more intense institutional and community dynamics, with the objective of achieving their rights, while the Canadian NGO represents a setting through which the participants individually accessed their rights already consolidated in the country.

KEYWORDS: Political participation; NGOs/AIDS; psychosocial factors; Human Rights; social vulnerability.

Em mais de 20 anos, o perfil da epidemia de HIV/ AIDS mudou muito, assim como as demandas de prevenção e de tratamento. Hoje, as pesquisas demonstram uma tendência em que predomina a infecção entre mulheres. Outra tendência que cresce está nos grupos mais vulneráveis sócio-econômico e culturalmente. Ou seja, a AIDS atinge cada vez mais pessoas que sofrem algum tipo de opressão e/ou são excluídas de direitos básicos. Este tipo de mudança do perfil epidemiológico é verificado tanto em países em desenvolvimento, quanto em países desenvolvidos, apesar das singularidades que marcam estas realidades.

A partir de dados do Programa Nacional de DST/AIDS do Ministério da Saúde (2003), é importante destacar alguns números sobre a epidemia no Brasil. No início da década de 80 até setembro de 2003 , foram notificados 277.154 casos de AIDS no Brasil, e, desse total, 197.340 em homens e $79.814 \mathrm{em}$ mulheres (2.5 homens para cada mulher). Ainda no ano de 2003, foram notificados mais 5.762 novos casos de AIDS, e, desse montante, 3.693 eram homens e 2.069 eram mulheres (1.8 homens infectados para cada mulher). Observamos um crescimento aproximado de 7\% no número de casos entre as mulheres. Outro dado alarmante é a crescente incidência da infecção em relação à faixa etária de 13 a 19 anos em adolescentes do sexo feminino.

As principais categorias de transmissão entre os homens são as relações sexuais que respondem por $58 \%$ dos 
casos de AIDS, desse montante as relações heterossexuais respondem apenas por $24 \%$. Entre mulheres, a transmissão do HIV pela via sexual é de $86,7 \%$.

No Canadá, o HIV/AIDS representa $2 \%$ do número de casos naAmérica do Norte (Ontario Advisory Committee on HIV/AIDS [OACHA], 2002). Desse percentual, 47\% dos casos estão localizados na província de Ontário. Neste país, cresce a incidência de mulheres, particularmente entre 15 e 29 anos, infectadas pelo vírus. Além disso, esta situação acentua-se nas comunidades urbanas mais pobres (OACHA, 2002).

Neste estudo comparativo entre Brasil e Canadá constata-se que, nos dois países, as pessoas que vivem com o HIV/AIDS têm tratamento adequado, recebem os remédios necessários, apoio social e material. O Brasil, em especial, despontou como um modelo possível de enfrentamento da epidemia dentro do conjunto dos países em desenvolvimento. Isto devido a uma longa história de lutas e militância de grupos sociais envolvidos com a cura e prevenção, médicos e demais profissionais de saúde, parentes e simpatizantes.

Recentemente vimos lograr o esforço de barateamento da produção de remédios, através da quebra de patente de alguns deles. Esta conquista permitiu que muitas pessoas recebessem remédios gratuitamente, pois dentro do Sistema Único de Saúde, qualquer pessoa, quer se trate na rede pública, quer na medicina privada, pode buscar nos serviços especializados, os medicamentos necessários, como forma de concretização do direito à saúde, especialmente o princípio que reza sobre a integralidade das ações de saúde (Berkman, Garcia, Munoz-Laboy, Paiva \& Parker, 2005; Galvão, 2005).

A associação entre HIV-AIDS e os direitos humanos mostra-se ao longo da história um importante instrumento de avanço na luta contra epidemia, principalmente no momento atual em que a AIDS adquire um perfil mais crônico de desenvolvimento, permitindo que as pessoas que convivem com o HIV-AIDS trabalhem e se desenvolvam como qualquer outra pessoa (Berkman et al., 2005; Câmara \& Lima, 2000; Galvão, 2005).

Contudo constatamos que estas pessoas ainda são alvos de atitudes discriminatórias e estigmatizantes. Esta situação torna-se mais complexa, na medida em que, a AIDS aparece como mais um ingrediente em meio a outros tipos de exclusão social. O sexo, a classe social e/ou a orientação sexual estão na base de muitos preconceitos e discriminações. Estas situações dificultam a construção da autonomia e o pleno exercício da cidadania das pessoas infectadas e dos seus próximos.

A atuação das ONGs/AIDS, na luta contra a epidemia, vem marcada pela solidariedade e pelo apoio afetivo dados àqueles que se abatiam pela doença. Eram amigos, companheiros (as) que se uniam e buscavam amenizar o sofrimento do portador e das pessoas próximas a eles (Câmara \& Lima, 2000; Chambre, s.d.). Além disso, lutam por uma condição de vida melhor para todos, através de pressão política e das lutas pela concretização dos Direitos Humanos e Sociais (Altman, 1995; Câmara \& Lima, 2000; Paker, 1994).

Focalizamos, neste estudo, a experiência de duas ONGs/ AIDS: Uma canadense situada no município de London, próximo a Toronto, a qual chamamos de ONG-Ca e em outra ONG que atua no município de Diadema pertencente à Grande São Paulo, a qual chamamos ONG-Br.

Ao debruçarmo-nos sobre as práticas de ONG's em contextos tão distintos, mas com características demográficas semelhantes (Tabela 1) buscamos:

Tabela 1. Comparação de dados sócio-demográficos referente aos municípios de London e Diadema*

\begin{tabular}{|c|c|c|}
\hline & London & Diadema \\
\hline População & 325,646 & 323,116 \\
\hline Pessoas por residência & 2.52 & 3.85 \\
\hline Mortalidade infantil/1000 habitantes & 6.1 & 21.3 \\
\hline Leitos Hospitalares & 1969 & 447 \\
\hline Pessoas com $2^{\circ}$ grau ou mais $(\%)^{\star *}$ & 74 & 9 \\
\hline Média mensal de ganhos ${ }^{\star * *}$ & $\$ 2,223.75$ & $\$ 542.00$ \\
\hline Taxas de desemprego (\%) & 9.60 & 15 \\
\hline Verbas município para investimentos (Can\$) & $435,000,000$ & $111,014,150$ \\
\hline
\end{tabular}


1. Descrever o histórico e as práticas institucional-sociais no combate da epidemia de HIV/AIDS.

2. Discutir a participação política como um processo em constante construção, condicionado por fatores psicossociais, contextualizados histórica e culturalmente.

\section{As ONGs/AIDS e a construção de novas formas de participação política}

Com base na compreensão do referencial dos Direitos Humanos como uma luta que entrecruza os níveis individuais e coletivos, percebemos que no contexto da trajetória dos Novos Movimentos Sociais ${ }^{1}$ da América Latina, destacando o Brasil, há significativas transformações da qualidade e formas de engajamento político; movimento este, do qual a luta contra AIDS faz parte.

Nas décadas de 1970 e 1980, os movimentos sociais buscavam uma transformação estrutural da sociedade, a maneira da pessoa se envolver no processo político implicava numa quase conversão aos "ideais revolucionários" que permeavam o momento histórico. Conscientização era a palavra chave de engajamento nas lutas sociais. Eram pessoas, de um modo geral, esclarecidas, com uma boa formação político-ideológica, baseada em referências da nova esquerda que, na época, reorganizava-se.

Na década de 1990, organiza-se, com mais força, grupos mobilizados por questões ligadas à opressão, vista sob outros ângulos: mulheres, negros e gays não vislumbravam seus desejos, pautas políticas e seus direitos contemplados nas "tradicionais lutas sociais de caráter macroestrutural". Nesses novos grupos de luta prevalecem os ideais de autonomia, emancipação e o respeito à diversidade. (Gohn, 1997; Sawaia, 2001). Também emerge forte, no meio destas novas organizações, a questão identitária e da subjetividade, estimulando uma enorme polissemia, que dá visibilidade e voz aos diversos grupos, antes invisíveis e sem força política.

A subjetividade explicita-se como fator que permite, canaliza e valoriza a expressão das singularidades, do mais humano e mais pessoal da experiência de cada participante, dentro do cotidiano da militância. Corporificavam-se as questões sociais e políticas das então chamadas minorias, não mais em bases apenas teóricas, ou enclausuradas em militâncias ortodoxas, mas, encarnadas nas dificuldades e exigências objetivas de seus membros.

Essa luta se confronta com as dinâmicas institucionais do mundo globalizado que coloca o envolvimento humano, a solidariedade e a participação como práticas extrínsecas à vida dos homens, subprodutos anacrônicos e indesejados, reforçando ações individualistas regidas pela lógica da produção de bens e serviços. (Sawaia, 1997; Sousa Santos, 2000).
A complexidade do processo de participação política pode ser melhor visualizada no esforço de compreensão da vivência institucional entre os militantes da AIDS. As instituições (no caso desta pesquisa as ONGs) têm o papel de mediação entre o sujeito e a sociedade (Enriques, 1997; Pages, 1976; Spink, 1996). É um lugar onde as contradições se evidenciam e onde as pessoas, no mundo contemporâneo, buscam apoio para realizarem seus projetos de vida.

Segundo Câmara e Lima (2000) as ONGs/AIDS ocupam um lugar híbrido, pois elas resgatam aspectos reivindicatórios, de controle social e assistenciais (medicação, atendimento ambulatorial e etc.), mas também são marcadas pela busca de respeito e de legitimidade na expressão da diversidade de modos de vida; herdeiras que são dos movimentos feminista, gay, negro e ecológico.

Nesta perspectiva, o movimento de AIDS incita-nos a buscar novos caminhos de construção da participação política, na medida em que compreendemos este como um caminho de fortalecimento psicossocial de sujeitos de direitos. Este fortalecimento pode ocorrer de maneiras distintas, em função, inclusive, da contextualização sócioeconômica e cultural deste fenômeno.

\section{Procedimento da pesquisa}

Foi utilizada uma articulação de procedimentos quantitativos e qualitativos, em várias fases do trabalho de investigação, que define o sujeito de pesquisa como aquela pessoa portadora ou não do HIV/AIDS que no momento da pesquisa atuava na ONG. Na literatura da área estas pessoas aparecem nomeadas como: voluntários, trabalhadores, ativistas e/ou militantes. Entendemos que denominar, nesta pesquisa, estas pessoas de participantes contempla esta diversidade de perfis.

No primeiro momento contextualizamos historicamente o surgimento e construção das entidades e analisamos documentos oficiais das ONGs. Em acréscimo foram, realizadas entrevistas semi-dirigidas com os presidentes das ONGs. Buscamos ainda, compreender os serviços prestados pelos Centros de Referência e Tratamento do HIV/ AIDS e outros serviços especializados envolvidos com as ONGs e, diretamente, ligados a atenção às DSTs/AIDS.

No segundo momento, conduzimos entrevistas divididas em duas partes: livres e semi-dirigidas. A entrevista livre visava captar os sentidos que os participantes atribuíam à descrição do fluxo e das cenas de sua vida cotidiana. $\mathrm{E}$ as semidirigidas tinham o objetivo de obter a reflexão dos participantes sobre: a vivência com o HIV/ AIDS, o papel da convivência na ONG/AIDS, a sua reflexão e vivência da noção de Direitos Humanos, e impressões e vivências com relação à comunidade e aos serviços públicos municipais de saúde. 
Pela ONG-Br foram entrevistados oito participantes e na ONG-Ca foram entrevistados cinco. Através deles, buscamos expressar a diversidade referente a: soropositivonegatividade, tempos distintos de participação e filiação na ONG, graus distintos de participação (dedicação maior ou menor), com diferentes perfis sócio-econômicos.

No terceiro momento foram enviados questionários a quase totalidade dos participantes das duas ONGs, com, aproximadamente, de $50 \%$ de retorno de cada uma delas. $\mathrm{Na}$ ONG-Br, obtivemos 23 questionários respondidos. Referente à ONG-Ca, obtivemos, como retorno, 34 questionários respondidos. Esta etapa se propôs a investigar as motivações e consequiências da participação nas organizações; caracterizar o perfil destes participantes e descrever a percepção deles sobre as ações das ONGs em relação a epidemia de AIDS.

A análise das entrevistas foi realizada segundo a Hermenêutica de Profundidade, proposta por John Thompson (1995). É importante mencionar que todos os procedimentos foram obtidos junto aos participantes, mediante consentimento livre e informado, e foram seguidas as recomendações sobre éticas de pesquisa consagradas no Brasil pela resolução da Comissão Nacional de Ética em Pesquisa-CONEP (Conselho Nacional de Saúde [CNS], 1996) e no Canadá. Os nomes dos entrevistados são fictícios.

\section{ONG-Ca: 20 anos de luta contra o HIVAIDS}

A ONG-Ca conta com 20 anos de formação, fundada por um pequeno grupo de ativistas do movimento gay. Eram pessoas de classe média-alta com uma boa formação cultural. A proposta desencadeadora era combater o medo, a ignorância e a falta de assistência médica que permeavam os primórdios da epidemia.

A ONG-Ca é uma Fundação apoiada pela AIDS Network and The Canadian AIDS Society, subsidiada por um grupo de organizações distritais e federais, que inclui entidades da sociedade civil e do governo. Ela investe, a cada ano, por cerca de 1.000.000 de dólares canadenses em suas ações, mais da metade é gasto com pessoal e benefícios. Um terço de sua verba é de origem privada.

Esta entidade coloca como missão o suporte, a defesa e a promoção de direitos, buscando mudanças no quadro da epidemia do HIV/AIDS. Por respeito à dignidade humana e à diversidade, a ONG-Ca cria uma atmosfera de aceitação e acolhimento, trabalha com objetivos de educação prevenção e, sobretudo, para que as pessoas que convivem com a infecção possam fazer suas escolhas de forma consciente. Desenvolve ações que diminuem os fatores sociais que impedem os cuidados aos portadores, destacando: a discriminação, a pobreza, a discriminação sexual, o isolamento social, a violência sexual e a criminalização da pobreza e da infecção.

\section{A ONG-Br: História e Ações Voltadas ao Combate da Epidemia}

A ONG-Br está sediada em Diadema, município da Grande São Paulo, foi oficializada em 1999. No entanto, sua história se inicia em meados de 1997, mediante discussões entre pessoas vivendo com HIV/AIDS e matriculadas no ambulatório especializado (SAE) da Unidade Básica de Saúde (UBS) do município. Estas pessoas passaram a se encontrar informalmente, após as consultas ou coleta de sangue para exames, com a intenção de criar um espaço de troca de experiências sobre dúvidas, angústias e perspectivas, frente ao fato de portarem o vírus HIV. Este foi o propósito da constituição desta ONG. A entidade aglutina um grande número de pessoas diferentes quanto ao grau de estudo, idade, sexo, orientação sexual, religião, local de moradia, profissão etc.

No estatuto e panfletos distribuídos pela ONG, a cidadania e a defesa dos direitos humanos são bandeiras de sua atuação: "A ONG-Br tem como missão promover a qualidade de vida, a cidadania, direitos humanos e a (re)inserção sócio-econômica e cultural em benefício dos portadores do HIV/AIDS, no município."

\section{Perfil dos participantes da ONG-Br e ONG-Ca}

Notamos que quase a totalidade dos participantes da ONG-Br tem menos de 40 anos, ou seja, estão numa fase bastante produtiva da vida. Cabe ressaltar que quase um terço de jovens tem menos de 24 anos (Tabela 2).

Embora a maior parte dos participantes, tenha declarado que está trabalhando, chama a atenção que, proporcionalmente, o número de desempregados na ONG-Br é quatro vezes maior. Acrescenta-se a isto o fato de um quarto dos participantes da ONG-Br serem trabalhadores informais ou, como afirmaram: "fazem bicos". A maioria dos participantes da ONG-Br que respondeu ao questionário, declarou uma renda familiar mensal entre dois e dez salários mínimos. $\mathrm{O}$ grau de escolaridade entre os participantes da ONG-Ca, observado no quadro abaixo, é maior que na ONG-Br. O nível universitário completo, entretanto, é maior na ONG-Br (Tabela 2).

Chama a atenção também a diferença das entidades quanto à orientação sexual: na ONG-Br menos de um quarto declarou-se homossexual e, na ONG-Ca, ao contrário, quase metade declarou-se homossexual. Este dado pode reforçar a tendência de mudança da epidemia, atingindo outros grupos sociais, a ONG-Br, por exemplo, é composta em mais da metade por mulheres heterossexuais, enquanto na ONG-Ca é quase metade dos participantes (Tabela 2). Também podem nos sugerir os dados que a 
Tabela 2. Caracterização dos participantes (em porcentagens)*

\begin{tabular}{lrr}
\hline & ONG-Ca & ONG-Br \\
\hline Participantes abaixo de 40 anos & 41.2 & 91.3 \\
Participantes que se identificaram como homossexuais & 38.2 & 8.7 \\
Participantes que estavam envolvidos em ações & 23.5 & 65.2 \\
comunitárias antes de se envolver com a ONG/AIDS. & & \\
Como participante da ONG, ele comparece às atividades & 38.2 & 60.9 \\
do grupo ao menos uma vez por mês. & 38.2 & 43.5 \\
Participante é voluntário na entidade pelo menos dois anos. & 79.45 & 56.5 \\
Participantes que vivem na região de London & 50 & 60,9 \\
e na Grande São Paulo por mais de cinco (5) anos & 50 & 39.1 \\
Mulheres participantes & 55.9 & 56.5 \\
Homens participantes & 44,1 & 47,8 \\
Sem filiação religiosa & 91,2 & 52,2 \\
Casado ou tem um companheiro (a) & 45,5 & 17,4 \\
Branco & 33,4 & 26,1 \\
2o grau completo & 15,2 & 13 \\
Superior incompleto & 48,5 & 65,2 \\
Superior completo ou mais & 3 & 13 \\
Trabalhando & & \\
Desempregado & & \\
\hline
\end{tabular}

ONG-Br tem um perfil participativo mais heterogêneo/ diversificado do que a ONG-Ca.

\section{As motivações para a participação na $\mathrm{ONG}-\mathrm{Br}$ e ONG-Ca}

Trazer alguns dos resultados sobre as motivações que desencadearam o envolvimento destas pessoas com uma ONG-AIDS, ajuda-nos a refletir sobre os fatores desencadeantes da participação política, pois sabemos que, com as transformações sociais e com as mudanças do perfil da epidemia, o desafio em construir estratégias que contemplem as novas demandas emergentes faz-se necessário.

Tanto na ONG-Br, quanto na ONG-Ca observamos que, foi considerado muito importante o desejo de ajudar aos outros, tornando-se um fator importante na decisão de participar (Tabela 3):

... A partir do momento que você está ajudando uma
pessoa, isso também te traz um retorno muito positi-
vo... como eu poderia te dizer... Se você vai dando o
que te fez sofrer, você vai passando pros outros, então
você vai se fortalecendo através daquilo. E a sua
dor, vai diminuindo ao passo que você está conse-
guindo ajudar outras pessoas neste mundo (Selma,
portadora - Brasil, 2003).

Esta tendência, que também aparece nos trabalhos de Stewart e Weinstein (1997) e de Ramirez-Valles e Brown
(2003), sugere-nos que a solidariedade é um aspecto importante, senão fundamental, na construção das ações do movimento de AIDS. Percebemos no desejo de ajudar aos outros, um fator identificatório que dirige tal desejo. Ramirez-Valles e Brown observaram nos voluntários que referiam esse desejo, o intuito de ajudar pessoas que tivessem uma mesma trajetória de vida ou características que os fizessem se sentir participantes de um mesmo grupo, por exemplo: serem hispânicos vivendo no EUA, ou de enfrentar as vicissitudes de se assumirem gays.

Na ONG-Br percebemos que este nível identificatório acontece entre pessoas que já tiveram experiências de exclusão/discriminação social. A identificação parece ser um aspecto importante na compreensão dos fatores motivadores da participação, também funciona como um elemento importante na eficácia das ações que tornam a pessoa mais consciente dos riscos de infecção:

Tive namorados, situações em que não usava preservativo, então... Sempre me mobilizou... A ser solidária, porque eu acho que qualquer um de nós poderia estar vivendo essa realidade, de portador do vírus HIV. Então, me engajar na luta, pra mim é uma obrigação de vida... (Sônia, não portadora - Brasil, 2003).

Outro aspecto importante, foi o desejo de troca de experiências. Este é expressivo nas duas entidades, eviden- 
ciando a ONG como um lugar privilegiado para se compartilhar esta vivência com o HIV/AIDS (Tabela 3). A troca de experiências está associada à luta contra a discriminação e estigma que estas pessoas sofrem. Observamos na grande maioria dos relatos das pessoas que chegaram à ONG, a fragilização e a necessidade de saber mais sobre a doença, em seus vários aspectos e, mais do que isto, de elaborar esta experiência para além da discriminação e do consequiente sentimento de culpa e de desvalorização. Aggleton e Warwick (1999), através da análise de respostas comunitárias à AIDS, constataram que a doença é geralmente vista como algo que vem de fora; o portador é o estrangeiro que trouxe a doença. No relato abaixo, podemos perceber o sofrimento causado pela discriminação:

"Difícil, é difícil. A informação está aí, mas ninguém acredita se não acontece com a própria pessoa. Então, acho que o pior não é nem a doença em si, é sim o preconceito das pessoas" (Vanessa, portadora-Brasil, 2003).

Minha igreja é contra o HIV e o homossexualismo, então eu não conto que sou voluntária. Meu marido sempre me faz assegurar de que após conduzir algum portador, eu limpe bem o carro. As palavras HIV/ AIDS assustam as pessoas. Se eles estiverem próximos pensam que vão pegá-la. Nós precisamos leválos a saber que não irão, e não precisão se assustar mais (Mary, não portadora - Canadá, 2003).

Dentro do movimento é que eu aprendi como lidar melhor com a AIDS, como lidar melhor comigo mesmo. Aprendi a importância de tomar os medicamentos na hora certa... hoje eu faço as coisas dentro do mundo da AIDS, voltado para algumas pessoas, $e$ isso me dá muita satisfação. Faço sem ter nenhum fim lucrativo, mas em compensação tenho outros lucros, talvez maiores do que dinheiro. Faço círculo de amizade muito grande; sei que sou útil para muitas pessoas (Antunes, portador - Brasil, 2003).
Meu status de cidadão mudou dramaticamente... Em poucos anos minha vida está indo num caminho muito diferente. Antes, eu era alcoolista e adicto. Desde que me tornei envolvido com a entidade, eu ganhei o status de trabalhador; daquele que ensina os outros. Eu ganhei respeito da comunidade (Brian, não portador de HIV - portador de hepatite C - Canadá, 2003).

O desejo de desenvolver uma atividade mais politizada é bastante expressivo na ONG-Br (Tabela 3). Dentre outros fatores, este resultado está associado com experiências anteriores em outros trabalhos comunitários, vivência de discriminação e estigma, enfrentamento de carências sociais e desemprego. Já na ONG-Ca, o envolvimento dos participantes com a entidade, dá-se de uma maneira muito mais linear e contratual, ou seja, os participantes buscam instrumentalizar sua ação para o enfrentamento das questões ligadas à soropositividade:

A minha vida? Com quatorze anos, eu já era metalúrgica. Fui metalúrgica, participei do movimento de 78, 79, 80, fiz greve, aquela coisa toda, aquele sonho todo... Comecei a trabalhar depois numa empresa, já em outro ramo, mas aí já na linha... Como operária... e aí, fui continuando o estudo, e aí, ao continuar os estudos fiz a opção por Serviço Social que também vêm um pouco dessa experiência de vida, né? [risos] Desses sonhos, acreditando na profissão como uma forma de realizar um pouco mais de justiça social... (Sonia, não portadora - Brasil, 2003).

Quando eu comecei a participar, eu ainda recebia assistência em minha casa. Através dos funcionários da ONG, eu comecei a trabalhar na recepção... O estafe da entidade me deu suporte quando precisava, eu não sabia muito sobre Hepatite C e HIV (Peter, não portador de HIV - portador de hepatite C - Canadá, 2003).

Tabela 3. Motivações para a participação (em porcentagens)*

\begin{tabular}{lcc}
\hline & ONG-Ca & ONG-Br \\
\hline $\begin{array}{l}\text { Participantes que estavam envolvidos em ações } \\
\text { comunitárias antes de se envolver com a ONG/AIDS. }\end{array}$ & 23.5 & 65.2 \\
$\begin{array}{l}\text { Como participante da ONG, ele comparece às atividades } \\
\text { do grupo ao menos uma vez por mês. }\end{array}$ & 38.2 & 60.9 \\
$\begin{array}{l}\text { Participante é voluntário na entidade pelo menos dois anos. } \\
\begin{array}{l}\text { Participante se uniu à entidade porque desejava ajudar } \\
\text { aos outros. }\end{array}\end{array}$ & 38.2 & 43.5 \\
$\begin{array}{l}\text { Participante juntou-se ao grupo por causa do desejo } \\
\text { de trocar experiências com outras pessoas que também }\end{array}$ & 78.4 & 82.6 \\
$\begin{array}{l}\text { convivem com o HIV/AIDS. } \\
\begin{array}{l}\text { Participante juntou-se ao grupo por causa do desejo } \\
\text { de tornar-se mais ativo politicamente. }\end{array}\end{array}$ & 23.5 & 56.5 \\
\hline
\end{tabular}

"Participantes que disseram "concordo" ou "concordo fortemente". 
Há uma compreensão de que o enfretamento da epidemia vai além de iniciativas individuais, ou seja, é uma luta construída coletivamente. Neste sentido, conforme observamos a partir das ONGs estudadas, a canadense politiza suas ações no sentido de construir estratégias que promovam condições de vida melhores para os usuários, divulgando e promovendo a aquisição de direitos e benefícios sociais. Já a ONG brasileira politiza suas ações exigindo e fiscalizando a qualidade de atendimento no serviço público, propondo ações afirmativas em relação às pessoas que vivem com o HIV/AIDS, ao mesmo tempo em que acolhe, conforta e cuida.

\section{Conseqüências da participação na ONG-Br e ONG-Ca}

Nas entrevistas os participantes da ONG-Br expressaram uma visão que valoriza imensamente a participação social, contudo são pessimistas em relação aos resultados obtidos junto ao Estado, principalmente no que se refere à garantia dos direitos. Associa-se a esta visão sentimentos e experiências de abandono, desconsideração, descasos, irresponsabilidades vividas na busca de direitos sociais. Experiência esta que não é compartilhada pelos participantes canadenses, que encontram a presença de um Estado (legislativo e rede de serviços) consolidado, sempre que acionam direitos e pautam reivindicações:

Direitos Humanos é tão complicado, geralmente se fala em direitos humanos, você lembra lá do preso que está na cadeia e tem que ser defendido por um monte de coisa. Só que o que levou esse cara a praticar assalto, roubo, crime, assassinato? O que representa os direitos humanos para as crianças hoje que estão na quinta série, se não tem emprego nem pra quem já tem a faculdade? Então eu acho que esse negócio de direitos, direito da gente, o maior direito de todas as pessoas, é trabalhar, é se conscientizar e buscar um amanhã melhor. Porque eu acho que hoje a gente não tem direito de nada (Selma, portadora - Brasil, 2003).

Alguns participantes da ONG-Br já demonstram uma clareza na associação entre HIV/AIDS e direitos humanos, percebem uma possibilidade de mudança do cenário de desamparo e de indignação. Sentem-se mais próximos da condição de cidadão. Silva (2002), em seu estudo com uma ONG no Rio de Janeiro, enfatiza a entidade como um lugar de afirmação da cidadania. Este sentimento é reforçado, por exemplo, pelas conquistas relacionadas ao acesso gratuito ao tratamento e medicamentos. Além disso, o participante percebe que tal conquista teve no movimento social um importante protagonista:

... porque hoje através dos direitos humanos eu consegui o quê? Hoje eu tenho medicamento de graça, trato o meu vírus HIV, trato com medicamentos, com profissionais, com médicos, tudo de graça. Nós luta- mos muito por isso, tivemos muita militância para chegar nisto. Temos guerra com a policia, guerra com o governo, pra poder ter esses ganhos. Quando eu falo, nós, eu falo de nós ONGs (Antunes, portador - Brasil, 2003).

Esta perspectiva evidencia os grandes desafios destes participantes e, para muitos, expressa o sentido da própria participação política. Sentem que é na luta coletiva que conseguirão melhores condições de vida para todos, ou seja, a convivência na ONG é um lugar onde podem delinear e incrementar as expectativas de uma comunidade mais cidadã, fraterna e saudável. Com diferentes níveis de consciência, estes participantes percebem que o grupo se fortalece a cada luta ganha e que a luta dos portadores de HIV incentiva outras ONGs e associações de portadores:

É... [pausa longa] direitos humanos... Eu acho que são condições básicas, essenciais de vida... Isso, infelizmente não é respeitado. A gente sabe das pessoas vivendo em condições precárias sem acesso às condições mínimas. Eu, enquanto cidadã, eu me pego muito pensando nisso. Eu falo que cada criança que nasce, é um pouco responsabilidade de cada um de nós... Cada pessoa sem estudar... sem formação. $O$ que remete a cada um de nós, colaborarmos, fazer... E assumir parte dessa responsabilidade... (Sonia, não portadora - Brasil, 2003).

Na ONG-Ca, a referência aos direitos humanos ocorre a partir da perspectiva da manutenção de um status quo já conquistado: a garantia de condições de vida e de tratamento para todos que vivem com o HIV/AIDS. Além disso, privilegia-se a garantia de direitos individuais, ou seja, cada um deve ser tratado igualmente e ter liberdade de expressão. A ONG é um lugar que as pessoas recebem informações sobre seus direitos e sentem-se mais fortalecidas como sujeitos individuais:

Quando eu decidi fazer mudanças na minha vida e fiquei num [processo] de reabilitação, sabendo que a assistente social podia me ajudar a ter meus direitos. Eu tinha direito a um salário, a casa e a outros equipamentos sociais... Meus próprios privilégios. $O$ direito das pessoas de ter ajuda quando precisam dela. Estejam elas em suas casas, institucionalizadas ou trabalhando (Brian - não portador de HIV - portador de Hepatite C - Canadá, 2003).

Quanto aos resultados relacionados ao fortalecimento para trabalhar em conjunto com outras pessoas da comunidade e, em outras causas sociais, percebemos uma porcentagem maior entre os participantes da ONG-Br (Tabela 4). Podemos pensar do ponto de vista da prática institucional que o processo de fortalecimento psicossocial destes participantes acontece diferentemente entre as duas entidades. Na ONG-Br a participação política faz parte de um processo coletivo marcado pela ênfase na troca de 
experiências entre os participantes e do esforço de construção coletiva da entidade. Todavia estes esforços são marcados por intensos e difíceis conflitos de relacionamentos, relembrando, a cada instante, a dificuldade de construção de espaços mais democráticos:

... senti que foi ignorância de certas pessoas, sabe?... Que é... Como se diz, não faz nada pra melhorar as coisas, tem um papel, só faz aquilo e acha que é a dona da situação. Então, assim, eu não consegui ainda engolir essas coisas... Por que você se sente... Acuada! É tipo assim, você mexe num pó de café, 'Não, não é esse não, não pode mexer nesse', você vai fazer um café não, tem que ser na mão, não pode nem usar a cafeteira e tem outras coisas assim e me irrita... Vamos nos sentir a vontade, vamos fazer pra melhorar... (Vanessa, portadora - Brasil, 2003).

A ONG-Ca serve de apoio e referência para seus agentes que enfrentam a síndrome e suas vicissitudes. A interrelação entre participante e entidade acontece dentro de uma estrutura bastante institucionalizada e altamente profissionalizada:

"Os programas da entidade são muito importantes. Eles educam as pessoas sobre a AIDS; sobre o que ela é realmente, e como podem ser infectados. Mais importante é que estes programas ajudam a quebrar barreiras" (Mary, não portadora - Canadá, 2003).

$\mathrm{Na}$ fala do presidente da ONG-Br, percebemos, desde o início da formação da entidade, uma preocupação maior no envolvimento da comunidade. Tem-se a perspectiva de que a entidade se constrói com a colaboração de cada uma das pessoas que a ela se agrega. A entidade é, nessa lógica, produto das inter-relações estabelecidas em seu próprio cotidiano. Além disso, desde a sua formação, é sustentada pela noção de que a AIDS traz consigo a exclusão social e o desrespeito aos direitos humanos e sociais, o que reforça a proposta de ser lugar de luta por melhores condições de vida para todos. Este esforço é reconhecido, na mesma medida em que, os participantes percebem que o respeito pela ONG na comunidade cresce (Tabela 4), assim como o número de novos participantes:

"Temos como missão promover a qualidade de vida, a cidadania, direitos humanos e a (re) inserção socioeconômica e cultural em beneficio dos portadores do HIV/ AIDS..."(Presidente da ONG-Br, portador-Brasil, 2003).

Após 20 anos de existência, há na ONG-Ca uma opção pelo fortalecimento institucional, tornando-se hoje um serviço dentro de uma infra-estrutura consolidada de combate à epidemia:

Nós não queremos perder a ligação com os movimentos de base, mas queremos ganhar a excelência da organização. A meta é sanar falha neste nível institucional" (Diretor executivo da ONG, 2003).

\section{Considerações Finais}

Através deste estudo podemos perceber que:

As duas ONGs possuem preocupações e demandas muito parecidas, ou seja, estão ligadas ao combate de situações de discriminação e estigma, acirrados por outras situações de exclusão social. Todavia, percebemos que os contextos institucionais diferem: A ONG-Ca tem sólida e complexa estrutura organizacional. Objetiva informar e fazer valerem direitos e conquistas sociais já consolidados. A ONG-Br tem estrutura organizacional modesta e está centrada na construção de direitos. Construção que está atrelada às singularidades do contexto sócio-histórico e das necessidades da população, conforme discute Sousa Santos (2000), quando se refere que a universalidade dos direitos humanos só pode concretizar-se dentro de uma delicada dialética com as realidades locais.

A diferença quanto ao processo de participação política é também acentuada. Na ONG-Ca, há uma infra-estrutura

Tabela 4. Mudanças como Resultado da Participação (em porcentagens)*

\begin{tabular}{lcc}
\hline & NGO-Ca & NGO-Br \\
\hline $\begin{array}{l}\text { Participantes se sentem mais empoderados para agir em defesa } \\
\text { de seus direitos políticos-civil como resultado da participação na entidade. }\end{array}$ & 52.9 & 73.9 \\
$\begin{array}{l}\text { Participantes se sentem mais motivados para trabalhar com outros } \\
\text { na comunidade como resultado de seu envolvimento com a entidade. }\end{array}$ & 61.8 & 87 \\
$\begin{array}{l}\text { Participantes se sentem mais motivados para se envolver com outras causas } \\
\text { ativistas como resultado da participação. }\end{array}$ & 32.4 & 56.5 \\
$\begin{array}{l}\text { Desde que se envolveu com a entidade, tem crescido o envolvimento destes } \\
\text { participantes com outros grupos comunitários. }\end{array}$ & 35.3 & 39.1 \\
$\begin{array}{l}\text { Na opinião dos participantes, o respeito à entidade pela comunidade } \\
\text { tem aumentado. }\end{array}$ & 29.4 & 78.3 \\
$\begin{array}{l}\text { Na opinião dos participantes, a participação de outras pessoas } \\
\text { da comunidade tem aumentado. }\end{array}$ & 20.6 & 69.6 \\
\hline
\end{tabular}

"Participantes que disseram "concordo" ou "concordo fortemente". 
consolidada em seus 20 anos de atuação e é amparada por uma forte rede governamental e não governamental. Enquanto a ONG-Br tem seis anos e depende de parcos recursos do governo e de doações de pessoas da sociedade civil. Neste contexto, a atuação dos participantes é decisiva para a própria sobrevivência da instituição.

Também pudemos observar diferenças quanto à natureza e qualidade da participação. Na ONG-Ca, o participante faz parte de uma organização estruturada, e lá, recebe apoio e suportes necessários, ou seja, ao integrar-se passa a viver de um "script" complexo e bastante predeterminado. A ONG é "quase” uma prestadora de serviços e expressa, na atualidade, o desejo de, cada vez mais, profissionalizar sua atuação. Por sua vez, na ONG-Br, em face de desafios e carências sempre novos, os ativistas são atores e autores de ações construídas coletivamente. Diante da falha, precariedade e mesmo da ausência do Estado, tornam-se ilimitados os desafios, as atribuições e as responsabilidades para os participantes.

Em ambas as realidades estudadas, apesar de todas as diferenças estruturais e processuais, o movimento de combate à AIDS suscitou novos caminhos de construção da participação política, na medida em que compreendeu e incorporou, em suas práticas cotidianas, o fortalecimento psicossocial de sujeitos de direitos.

\section{Notas}

1 Segundo Eder Sader (1995) este conceito refere-se a emergência de novos atores sociais no cenário das políticas públicas, expresso pelos por grupos de pessoas reivindicando melhores condições de vida, por exemplo: luz, água, esgoto, etc. Assim se inaugura novas formas de se fazer política, não se restringindo aos 'modelos tradicionais' dos sindicatos e dos partidos políticos.

\section{Referências}

Aggleton, P., \& Warwick, I. (1999). Community responses to AIDS. In Sex and youth: Contextual factors affecting risk for HIVIAIDS: A comparative analysis of multi-site studies in developing countries. Geneva, Switzerland: UNAIDS.

Altman, D. (1995). Poder e comunidade, respostas organizacionais e culturais à AIDS. Rio de Janeiro, RJ: Editora da Universidade Estadual do Rio de Janeiro.

Berkman, A., Garcia, J., Munoz-Laboy, M., Paiva, \& V., Parker, R. (2005). A critical analysis of the Brazilian response to HIV/AIDS: Lessons learned for controlling and mitigating the epidemic in developing countries. American Journal of Public Health, 95(7), 1162-1172.

Câmara, C., \& Lima, R. M. (2000). Histórico das ONGs/AIDS e sua contribuição no campo das lutas sociais. Cadernos $A B O N G$, São Paulo, 28, 29-74.

Chambre, S. (s.d). Responding to uncertainty bearing witness: Volunteering as collective behavior in the AIDS epidemic, 1981-1988. New York: Center for the Study of Philantropy.

Conselho Nacional de Saúde. Resoluções. Retirado em jan. 2003, de http://conselho.saude.gov.br
Enriques, E. (1997). A organização em análise. Petrópolis, RJ: Vozes.

Galvão, J. (2005). Brazil and access to HIV/AIDS drugs: A question of human rights and public health. American Journal of Public Health, 95(7), 1110-1116.

Gohn, M. G. (1997). Teoria dos movimentos. São Paulo, SP: Loyola. Ontario Advisory Committee on HIV/AIDS. (2002). A proposed HIV/AIDS strategy for Ontario to 2008 [Brochure]. Toronto, Canadá: Authors.

Pages, M. (1976). A vida afetiva dos grupos. São Paulo, SP: Editora da Universidade de São Paulo.

Paker, R. (1994). A construção solidariedade: AIDS, sexualidade e política no Brasil. Rio de Janeiro, RJ: Relume-Dumará.

Programa Nacional DST/AIDS. (2003) Boletim epidemiológico. Retirado em ago. 2004, de http://www.AIDS.gov.br

Ramirez-Valles, J., \& Brown, A. (2003). 'Latinos' community involvement in HIV/AIDS: Organizational and individual perspectives on volunteering. AIDS Education and prevention, 15, 90-104.

Sader, E. (1995). Quandonovos personagens entram em cena: Experiências e lutas dos trabalhadores da grande São Paulo 19701980. São Paulo, SP: Paz e Terra.

Sawaia, B. (1997). A legitimidade subjetiva no processo de participação social na era da globalização. In B. Sawaia (Ed.), Estudos sobre comportamento político - Teoria e pesquisa. Florianópolis, SC: Letras Contemporâneas.

Sawaia, B. (2001). Participação social e subjetividade. In M. Sorrentino (Ed.), Ambientalismo e participação na contemporaneidade (pp. 75-87). São Paulo, SP: FAPESP.

Silva, L. M. P. (2002). Construção de identidade em um espaço comunicativo: A experiência do Grupo Pela Vida. São Paulo, SP: Impulso.

Spink, P. K. (1996, jan./jun.). A organização como fenômeno psicossocial: Notas para uma redefinição da psicologia do trabalho. Psicologia e Sociedade: Revista da Abrapso, 8(1), 174-192.

Sousa Santos, B. S. (2000). Por uma concepção multicultural de Direitos Humanos. In G. Capinha \& B. Feldman-Bianco (Eds.), Identidades: Estudos de cultura e poder (pp. 19-39). São Paulo, SP: Hucitec.

Stewart, E., \& Weinstein, R. S. (1997). Volunteer participation in context: Motivations and political efficacy within three AIDS organizations. American Journal of Community Psychology, 25(6), 809-837.

Thompson, J. B. (1995). Ideologia e cultura moderna. Petrópolis, RJ: Vozes.

Carlos Roberto de Castro-Silva é graduado em Filosofia pela Universidade de São Paulo (USP), e em Psicologia pela Pontifícia Universidade Católica de São Paulo (PUC-SP). Doutor em Psicologia Social pela USP. Pós-Doutor em Ciências Sociais pela University of Western Ontario, Canadá. Atualmente é Professor Titular da Universidade Cruzeiro do Sul, na Graduação (Psicologia) e na Pós-Graduação em Políticas Sociais e

Ciências da Saúde. Pesquisador do Núcleo de Estudos e Prevenção da AIDS da USP (NEPAIDS). Endereço para correspondência: Rua Lavradio, 147, apto. 51, São Paulo, SP, 01154-020. Telefone (011) 3667-0068 carobert@usp.br 
Castro-Silva, C.R.; Hewitt, W. E.; Cavichioli, S. "Igualdades e dessimetrias: a participação política em ONGs HIV/AIDS..."

W. E. (Ted) Hewitt é Ph.D. Vice-Presidente de Pesquisa e Relações Internacionais e Professor do Departamento de Sociologia da University of Western Ontario.

hewitt@uwo.ca

Silvana Cavichioli é Mestre em Serviço Social e

Doutora em Psicologia Social pela PUC-SP.

Atualmente é Professora do Curso de Serviço social do Ambulatório de Saúde Mental do Município de São Paulo.
Igualdades e dessimetrias: a participação política em ONGs HIV/AIDS do Canadá e do Brasil

Carlos Roberto de Castro-Silva,

W. E. (Ted) Hewitt e Silvana Cavichioli

Recebido: 27/12/2006

Aceite final: 26/03/2007 